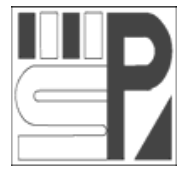

Science Press

\title{
Sand flux estimation during a sand-dust storm at Tazhong area of Taklimakan Desert, China
}

\author{
XingHua $\mathrm{YANG}^{1,3 *}$, XiaoLiang $X \mathrm{U}^{2,4}$, Qing $\mathrm{HE}^{1,3}$, Ali Mamtimin ${ }^{1,3}$, Bo $\mathrm{YU}^{2,4}$, ShiHao TANG ${ }^{5}$ \\ ${ }^{1}$ Institute of Desert Meteorology, China Meteorological Administration, Urumqi 830002, China; \\ ${ }^{2}$ Xinjiang Institute of Ecology and Geography, Chinese Academy of Sciences, Urumqi 830011, China; \\ ${ }^{3}$ Desert Atmosphere and Environment Observation Experiment of Taklimakan Station, Tazhong 841000, China; \\ ${ }^{4}$ Graduate University of Chinese Academy of Sciences, Beijing 100049, China; \\ ${ }^{5}$ National Satellite Meteorological Center, China Meteorological Administration, Beijing100081, China
}

\begin{abstract}
In this paper, the sand transport during a sand-dust storm in the Tazhong area of the central Taklimakan Desert from 11:29 to 23:56 on July 19, 2008 was observed and measured in real time. The sand flux at Tazhong was estimated using sand transport empirical formulas. The critical friction velocity at Tazhong was 0.24 $\mathrm{m} / \mathrm{s}$ and the functional relation between the wind speed and sediment discharge at the height of $2 \mathrm{~m}$ was established. It was also found that the calculated values by Lettau's sediment discharge formula were close to those of the instrument measurements. The horizontal sand flux and the vertical sand flux during this sand-dust storm at Tazhong were respectively $258.67 \times 10^{-4} \mathrm{~kg} /(\mathrm{m} \cdot \mathrm{s})$ and $40.07 \times 10^{-7} \mathrm{~kg} /\left(\mathrm{m}^{2} \cdot \mathrm{s}\right)$.
\end{abstract}

Keywords: friction velocity; sand transport flux; Taklimakan Desert

Sand-dust storms not only lead to serious deterioration of air quality and endanger human health, but also impose negative effects on society and the economy. The key point in identifying the source of sand-dust storms and controlling it effectively is estimating the sand transport flux during sand-dust storms accurately. There are varieties of models for estimating the surface dust transport flux, but the results of these models have shown great differences. It was estimated that around the world about 1,000-5,000 Tg/a of sand-dust particles are transported into the atmosphere from the ground (Tegen et al., 1994), and the estimation by Duce (1980) was 1,000-2,000 Tg/a. On the basis of the element concentrations of mineral dust (Al, Fe, $\mathrm{Mg}$ and $\mathrm{Si}$ ) in the 12 desert stations in China, it has been estimated that there are about $800 \mathrm{Tg} / \mathrm{a}$ of sand-dust particles transported into the atmosphere (Zhang et al., 1997). The arid desert region in Northwest China is one of the world's main sources of atmospheric dust, and the Taklimakan Desert in the Tarim Basin is an important part of the source of sand-dust storms in China. Many scholars have analyzed the sand-dust storm weather in this region in terms of climate, distribution pattern and other factors (Shalaimaiti, 1996; Liang et al., 2005; Huo et al., 2006; Abuduwaili et al., 2010), but little research has focussed on the sand transport flux of the sand-dust storms in this region.

The sand flux can be obtained by instrument measurements or empirical equations. Because of the imperfect relationship between instrument measurements and theory, estimation through empirical equations is prevalent at present. In this paper, we report field tests and observations during a sand-dust storm that occurred in the central area of the Taklimakan Desert on July 9, 2008, and compare the sediment flux during the storm calculated using empirical equations with the results of direct instrument measurements.

Received 2011-01-24; accepted 2011-03-29

* Corresponding author: XingHua YANG (E-mail: yxh19820218@163.com) 


\section{Data collecting}

The weather data were collected from an 80-meter gradient tower observation system at Tazhong Atmospheric Environment Observation Experiment Station located in the central area of the Taklimakan Desert. This observation system included 10 levels of heights which were $0.5 \mathrm{~m}, 1 \mathrm{~m}, 2 \mathrm{~m}, 4 \mathrm{~m}, 10 \mathrm{~m}, 20 \mathrm{~m}$, $32 \mathrm{~m}, 47 \mathrm{~m}, 63 \mathrm{~m}$ and $80 \mathrm{~m}$, and the basic elements that were obtained included horizontal wind direction, wind speed, temperature and relative humidity $(\mathrm{RH})$. The type of the anemometer sensor was WAA151 produced by the Finnish VAISALA Corporation. The wind speed range of the sensor was $0.4-75 \mathrm{~m} / \mathrm{s}$, and the wind cup started to revolve when the wind speed was no less than $0.35 \mathrm{~m} / \mathrm{s}$, with a measuring accuracy of $0.17 \mathrm{~m} / \mathrm{s}$. The thermograph was the HMP45D (QMH102) temperature transmitter with an anemometer sensor produced by the same company. The measuring range of the temperature was $-39.2^{\circ} \mathrm{C}$ to $60^{\circ} \mathrm{C}$ and the measuring accuracy was $\pm 0.2^{\circ} \mathrm{C}$ (at $20^{\circ} \mathrm{C}$ ). The database types of the 80 -meter gradient tower detection system include the average data per second, minute and hour. The data utilized in this paper are the average data per minute.

In order to study the sand transportation in the Tazhong area, BSNE (Big Springs Number Eight) Gradient Sand Traps were respectively placed on the flat sand sheet and on the top of a tall sand dune. The BSNE Gradient Sand Trap is commonly used internationally and the efficiency of trapping sand is more than 90\% (Shao et al., 1993). These sand-trapping boxes of the BSNE Gradient Sand Traps can simultaneously collect sand flux at six sediment layers. The heights for the sand-trapping boxes were set up at 5 $\mathrm{cm}, 10 \mathrm{~cm}, 20 \mathrm{~cm}, 50 \mathrm{~cm}, 100 \mathrm{~cm}$ and $200 \mathrm{~cm}$. Before the sand-dust storm started, the sand-trapping boxes were all cleaned, and as soon as the storm was over the sand samples were collected from the sand-trapping boxes and loaded into sealed bags. After that, the collection time, the period of the sand-dust storm and wind conditions were all recorded and the sand samples were all weighed. Also prior to the sand-dust storm, H11B wind erosion sensors (produced by the US Sensit Corporation) were set up above flat sand at the heights of $5 \mathrm{~cm}$ and $10 \mathrm{~cm}$.
Through many controlled experiments between laboratories and field, the wind erosion sensor has shown good performance and has produced good experimental results. By recording the number of the particles in collision with the sensor and the impact energy during the sand storm, and referring to the gradient velocity of the wind, the start of sand particle movement can be determined.

\section{Calculation of sediment fluxes}

The types of dust flux include horizontal dust flux, which means sand transport rate, and vertical sand transport flux, respectively represented by $\mathrm{Q}$ and $\mathrm{F}$. In the range from the surface to the observation height, Q represents the quality of sand particles which cross the sensor in a unit time and a unit width. The physical significance of $F$ is that, at a measured height above the ground, the quality of the sands transported from the surface into the atmosphere within a unit time per unit area can be measured.

Since the middle of the $20^{\text {th }}$ century, many scholars have researched the relationship between air flow and sand particle flux. Based on field observations or wind tunnel simulation tests, sand transport rate models have been put forward by different researchers (Table 1).

Table 1 Representative sediment discharge models

\begin{tabular}{ll}
\hline Author (year) & Formula \\
\hline Bagnold (1941) & $Q=C_{1} \sqrt{\frac{d}{D}} \frac{\rho}{g} u_{*}^{3}$ \\
Kawamura (1951) & $Q=C_{2} \frac{\rho}{g}\left(u_{*}-u_{*_{t}}\right)\left(u_{*}+u_{*_{t}}\right)$ \\
Zingg (1953) & $Q=C_{3}\left(\frac{d}{D}\right)^{0.75} \frac{\rho}{g} u_{*}^{3}$ \\
Owen (1964) & $Q=C_{4} \frac{\rho u_{*}^{4}}{g}\left[1-\left(\frac{u_{* t}}{u_{*}}\right)^{2}\right]$ \\
Kadib (1965) & $Q=C_{5} \rho_{S}\left[\frac{P}{(1-P)}\right]\left[\frac{\left(\rho_{S}-\rho\right) g d^{3}}{\rho}\right]^{0.5}$ \\
Hsu (1971) & $Q=C_{6} e^{4.79 d-0.47} \frac{u_{*}^{3}}{(g d)^{1.5}}$ \\
Lettau (1978) & $Q=C_{7}\left(\frac{d}{D}\right)^{N}\left(\frac{\rho}{g}\right)\left(u_{*}-u_{* t}\right) u_{*}^{2}$ \\
Sorensen (1991) & $Q=C_{8} \rho u_{*}\left(u_{*_{t}}-u_{* t}\right)\left(u+7.6 u_{* t}+205\right)$ \\
\hline
\end{tabular}

Note: $Q$ is horizontal sand flux; $d$ is sand grain size; $D$ is standard grain size, which is $250 \mu \mathrm{m} ; \rho$ is air density; $\rho_{s}$ is density of the sands; $g$ is gravity acceleration; $u *$ and $u_{*}$ are airflow friction velocity and the critical airflow friction velocity, respectively; $P$ is some kind of normal probability; $b$ and $N$ are indices; $C_{1}-C_{8}$ are coefficient indices, with the values of $1.8,2.78,0.83,0.25,0.025,0.0001,4.2$ and 0.0004 , respectively. 
Many researchers (Gillette et al., 1988; Marticorena et al., 1995; Shao et al., 1996; Lu et al., 1999) have researched vertical sand flux, and varied computation models have been established. Although the theory of sand flux models is relatively robust (Marticorena et al., 1995; Shao et al., 1996; Lu et al., 1999), the form of the models is complex. Large numbers of parameters are required in the computational process and some parameters are difficult to determine, so there is difficulty in actual application. The computation model by Gillette (1988) is very simple in form and merely two parameters, $u *$ and $u_{*}$, are required, which is suitable for simple or approximate estimation. The specific formula is as follows:

$$
F=\left\{\begin{array}{l}
C_{2} u_{*}^{4}\left(1-\frac{u_{*_{t}}}{u_{*}}\right) u_{*}>u_{* t}, \\
0 \quad u_{*} \leqslant u_{*_{t}},
\end{array},\right.
$$

where $C_{2}$ is a coefficient, with the value of $1.4 \times 10^{-15}$ $\mathrm{g} /\left(\mathrm{cm} \cdot \mathrm{s}^{3}\right)$.

\section{Calculation of sand transport flux}

In the computation of the sand flux, $u *$ and $u_{*}$, respectively the friction velocity and the critical friction velocity, are both critical parameters requiring accurate calculation. So in this research, these two parameters during the sand-dust storm needed to be determined first.

\subsection{Friction velocity}

Whether individual soil particles can break away from the surface depends on the join forces of the external aerodynamics and resistance (including gravity and internal viscous force). In blown sand physics, $u *$, the friction velocity, is used to reflect the aerodynamic force imposed on sand particles. According to existing observations and experimental results, sand-dust particles will break away from the surface and enter the atmosphere as soon as $u_{*}$ exceeds a certain threshold (critical friction velocity). As for the calculation of $u *$, the formula proposed by Bagnold (1941) was based solely on the wind speeds of two layers, which was inclined to cause errors. In this paper, based on the Monin-Obukhov similarity theory and using wind speed and temperature data of two layers, an aerodynamics method was applied to calculate the friction velocity $u_{*}$, calculated as formula (2) (Zhang et al.,
2001):

$$
\frac{k z}{u_{*}} \frac{\partial u}{\partial z}=\phi_{m} .
$$

Where $u *$ represents the friction velocity $(\mathrm{m} / \mathrm{s}) ; k$ is Kerman constant (generally 0.4); $z$ represents the height $(\mathrm{m}) ; u$ is the wind speed $(\mathrm{m} / \mathrm{s}) ; \phi_{m}$ is the MoninObukhov similarity function of the wind and can be calculated with formula (3).

$$
\phi_{m}(\zeta)=\left\{\begin{array}{ll}
(1-16 \zeta)^{-0.25} & \zeta \leqslant 0 \\
(1+5 \zeta) & \zeta<0
\end{array} .\right.
$$

Where $\zeta$ is the Monin-Obukhov atmospheric stability parameter, which is $z / L$. This can be approximately determined using the Businger-Dyer relational expression (4):

$$
\zeta=\left\{\begin{array}{ll}
R_{i} & R_{i}<0 \\
R_{i} /\left(1-5 R_{i}\right) & R_{i} \geqslant 0
\end{array} .\right.
$$

Where $R_{i}$ is the gradient Richardson value, which can be calculated with formula (5):

$$
R_{i}=\frac{g \sqrt{z_{1} z_{2}}}{\bar{T}} \frac{\Delta T}{(\Delta u)^{2}} \ln \left(\frac{z_{2}}{z_{1}}\right) .
$$

Where $\bar{T}$ represents the average absolute temperature $(\mathrm{K})$ of the two selected air layers $\left(\mathrm{z}_{1}, \mathrm{z}_{2}\right)$, and $\Delta T$ and $\Delta u$ respectively represent the temperature difference and wind-speed difference between the upper and lower heights of the two air layers.

Using the above-mentioned formulas and utilizing the temperature and wind-speed data at the heights of both $1 \mathrm{~m}$ and $2 \mathrm{~m}$ which were provided by the 80-meter gradient tower detection system at Tazhong, the friction velocity $(u *)$ during the sand-dust storm, which lasted from 11:29 to 23:55 on July 19, 2008, could be calculated as Fig. 1. The friction velocity varied with the variation in wind speed, that is, the larger the wind speed, the larger the friction velocity (Fig. 1). The friction velocity appeared to be mainly affected by wind speed. We observed that the larger the wind speed was, the stronger was the turbulence near the ground, which led to a greater intensity of sediment transport, and larger $u_{*}$. This result is consistent with the conclusions of the study in Xiaotang region by He et al. (2008).

\subsection{Critical friction velocity}

Critical friction velocity $u_{*_{t}}$ is the threshold of friction velocity at which sand particles start to be raised from 


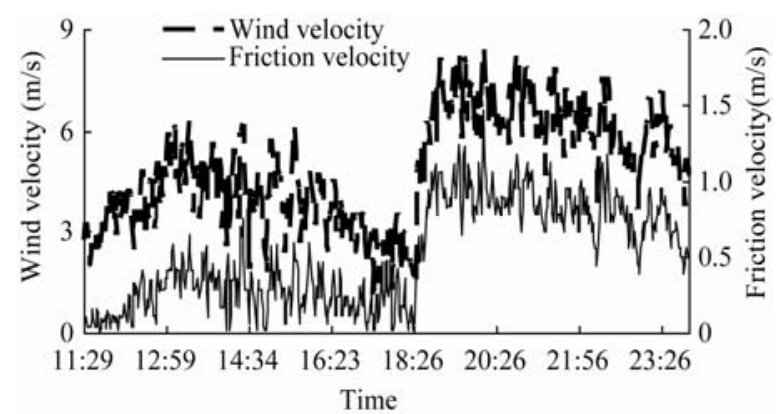

Fig. 1 The wind velocity over $z=2$ meters and friction velocity at Tazhong on July 19, 2008

the surface. Different critical friction velocities characterize how the ground surface hinders sand particles from rising (Shen et al., 2004). Since the surface features are composed of factors including mechanical and mineral composition, vegetation coverage as well as coverage of other roughness elements, water and salt content, topography and slope trend, human management and utilization, and other factors, the mechanism by which wind exerts influence on dust emission is complicated. There are differences in the values of $u *_{t}$ under different ground surface conditions. For sand particles of a given grain size, the critical friction velocity will be affected by soil properties especially soil water content, and vegetation. Therefore, it is relatively complicated to obtain an accurate value for the critical friction velocity. At present, the formula by Shao et al. (2000) is considered to be the most accurate in theory, and the expression is shown as formula (6):

$$
u_{*_{t}}=H(\omega) R(\lambda) \sqrt{A_{N}\left(\frac{\sigma g d}{\rho}+\frac{\varepsilon}{\rho d}\right)} a .
$$

Where $A_{N}$ and $\varepsilon$ are empirical constants $(0.0123,300$ $\mathrm{kg} / \mathrm{s}^{2}$ respectively); $\sigma$ is the density of sand particles $\left(2,650 \mathrm{~kg} / \mathrm{m}^{3}\right) ; \rho$ is the air density $\left(1.23 \mathrm{~kg} / \mathrm{m}^{3}\right) ; g$ is the gravitational acceleration which is approximately $9.7975 \mathrm{~m} / \mathrm{s}^{2}$ at Tazhong; $d$ is the grain size of sand particles $(\mu \mathrm{m}) ; H(\omega)$ and $R(\lambda)$ characterize the obstruction to dust emission imposed by soil moisture and vegetation respectively. The detailed calculations can be seen in Shen et al. (2005).

According to observation, the average grain size of the sand particles on the ground surface at Tazhong is $136 \mu \mathrm{m}$, and the average moisture content of the sand soil, at a depth of $0-10 \mathrm{~cm}$ is $3.2 \%$, which is lower than the marginal value of $5 \%$ (Shao et al., 2001). The vegetation factor in the Tazhong area can be ignored.
So the values of $H(\omega)$ and $R(\lambda)$ are both equal to 1 . After importing the parameters into formula (6) and computing them, the critical friction velocity, $u_{*}$, in the Tazhong area was found to be $0.24 \mathrm{~m} / \mathrm{s}$.

Estimation through empirical equations has empirical and regional limitations. In order to obtain more precise critical friction velocity for the Tazhong area, estimations for the same sand-dust storm were made based on recorded instrument values. Figure 2 shows the relation between the number of hitting sand particles and the friction velocity, which was measured by H11B wind erosion sensor. According to Fig. 2, sand particles begin to move when $u *$ reaches $0.20 \mathrm{~m} / \mathrm{s}$ and they begin accelerating when $u_{*}$ exceeds $0.22 \mathrm{~m} / \mathrm{s}$, with the number of hitting sand particles increasing. From this we can determine that the range for the critical friction velocity in the Tazhong area is $0.20-0.25 \mathrm{~m} / \mathrm{s}$, which coincides with the result by the empirical equation (Shao et al., 2005). After much consideration, the value of the critical friction velocity chosen for the Tazhong area was $0.24 \mathrm{~m} / \mathrm{s}$, that is, $u_{* t}=$ $0.24 \mathrm{~m} / \mathrm{s}$. This value is smaller than the critical friction velocity of the Gobi desert in Dunhuang, which is 0.43 $\mathrm{m} / \mathrm{s}$ (Shen et al., 2004), but it is close to the critical friction velocity of the farmland in Dunhuang, which is $0.3 \mathrm{~m} / \mathrm{s}$. This value in Tazhong is also approximately equal to that in Yanchi area which is $0.32 \mathrm{~m} / \mathrm{s}$ (Wang et al., 2007). The Gobi desert in Dunhuang is covered by fine gravel and mobile, relatively coarse sand particles, so the critical starting velocity is relatively large. The sands in the Tazhong area are finer, have no vegetation cover, and have a lower topsoil moisture content than in the Dunhuang and Yanchi areas. Therefore, it is reasonable to expect that the critical starting velocity in the Tazhong area would be relatively small.

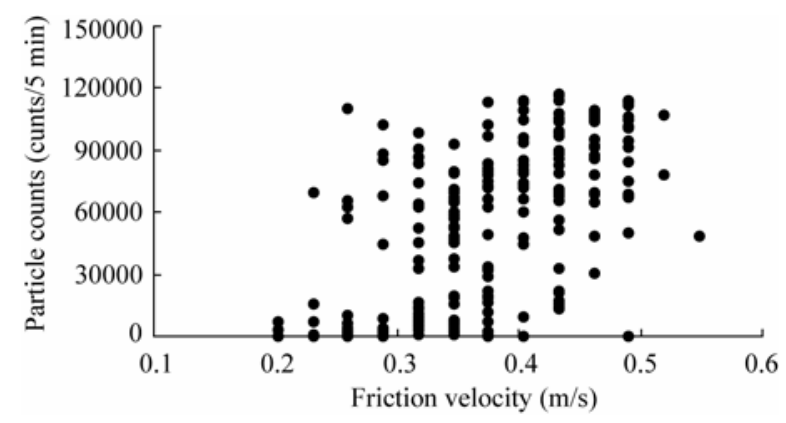

Fig. 2 The relationship between friction velocity and particle counts was measured by wind erosion sensor 


\subsection{Computation of the sand flux during the sand- dust storm}

As there are differences between the values of horizontal sand flux predicted by different formulas ( $\mathrm{Lv}$, 2004), the sand flux in this paper was calculated using multiple formulas. We used the formulas of Bagnold, Zingg, Kawamura and Lettau. The value for vertical sand flux in this paper was calculated using Gillette's formula. Importing the above-mentioned parameters into the corresponding formulas, the horizontal and vertical sand transport flux could be obtained, as shown in Fig. 3.

It can be seen from Fig. 3 (a) and (b) that the results for sand transport flux calculated by different formulas are very similar. The wind speed was unstable from 11:29 to $17: 00$, so the curve that reflects sand emission is not continuous. The wind speed is relatively high and stable from 17:00 to 23:00, and the curve is continuous and the amount of wind-blown sands is relatively large. The variations in sand transport flux were coincident with those of friction velocity, while the friction velocity was influenced by the wind speed (Fig. 1 and Fig. 3). So it can be stated that the wind speed is the principle factor determining sand flux.

The results of Bagnold's formula for horizontal sand flux follow closely the pattern of the results from the Zingg formula, but on the whole, the sand flux by Bagnold's formula is larger than that of Zingg. In this sand-dust storm, the average horizontal sand flux by Bagnold, Zingg, Kawamura and Lettau's formulas are $191.67 \times 10^{-4} \mathrm{~kg} /(\mathrm{m} \cdot \mathrm{s}), 92.17 \times 10^{-4} \mathrm{~kg} /(\mathrm{m} \cdot \mathrm{s}), 522.5 \times$ $10^{-4} \mathrm{~kg} /(\mathrm{m} \cdot \mathrm{s})$ and $258.67 \times 10^{-4} \mathrm{~kg} /(\mathrm{m} \cdot \mathrm{s})$ respectively. Thus it can be seen that there are large differences between the calculated results of each formula; the result by Kawamura's formula is the largest, approximately 6 times that produced by the Zingg formula.
Figure 3 (c) shows that the variations in the vertical sand flux coincide with those of the horizontal sand flux in this sand-dust storm in the Tazhong area. The average vertical sand flux during this sand-dust storm was $40.07 \times 10^{-7} \mathrm{~kg} /\left(\mathrm{m}^{2} \cdot \mathrm{s}\right)$, which is larger than that of the Gobi desert in Dunhuang (Lv et al., 2004; Shen et al., 2004) and that of the arid steppe in the Inner Mongolian autonomous region (Shen et al., 2008) by an order of 1-2 magnitudes. This difference is mainly caused by different surface features and different wind speeds between these regions.

\section{Comparative analysis of thetheo- retical values and measured results of sand flux}

In order to test the applicability of the theoretical models of sand flux in the Tazhong area, an equation to extrapolate results was established based on previous studies. The functional relationship is based on the results obtained from square-mouth sand traps (which can only measure the sand flux at the height of $1 \mathrm{~m}$ and in one direction) and our measured results at 6 different heights. The horizontal sand flux at the height of $2 \mathrm{~m}$ can be obtained by this extrapolation. Then the empirical formula expressing the functional relation between wind speed and sand flux at the height of $2 \mathrm{~m}$ can be created as follows:

$$
Q=10^{-6} u^{4.257}\left(R^{2}=0.9975\right) \text {. }
$$

Where $Q$ represents the horizontal sand flux within the height of $2 \mathrm{~m}$ above the surface and in the width of $1 \mathrm{~m}$, with units in $\mathrm{kg} /(\mathrm{m} \cdot \mathrm{s}) . u$ represents the wind speed at $2 \mathrm{~m}$ at which sand movement begins. By comparing the above empirical equation with Bagnold, Zingg, Kawamura and Lettau's formulas (Fig. 4), it
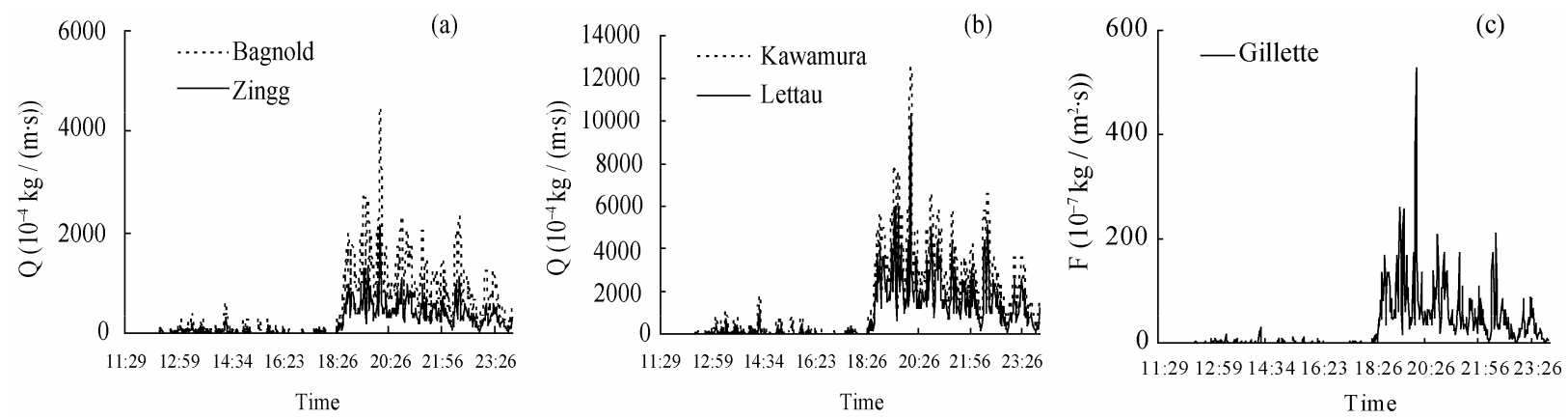

Fig. 3 The variations of horizontal (a, b) and vertical (c) sand transport flux with time in the Tazhong area on July 19, 2008 
can be seen that the calculated results of sand transport flux by the formulas are all close to the measured results when the wind speed is less than $12.0 \mathrm{~m} / \mathrm{s}$. However, the results show increasing differences as the wind speed exceeds $12.0 \mathrm{~m} / \mathrm{s}$. The results by Bagnold and Zingg's formulas are smaller than the measured result, with Zingg's result being the minimum. The sand flux by Kawamura's formula is always larger, and only the results by Lettau's formula are close to the measured results: the two curves almost coincide when the wind speed is smaller than $20.0 \mathrm{~m} / \mathrm{s}$, but when the wind speed is over $20.0 \mathrm{~m} / \mathrm{s}$ the measured results exceed the calculated results, although still very close to each other. Even if taking into account the instrument efficiency of the sand traps, the results by Lettau's formula are still the closest to the measured sand flux in the Tazhong area. As a result, the average horizontal sand flux during this sand-dust storm is approximatively identified as $258.67 \times 10^{-4}$ $\mathrm{kg} /(\mathrm{m} \cdot \mathrm{s})$. The vertical sand flux will not be discussed further in this paper, because no field tests or observations were carried out.

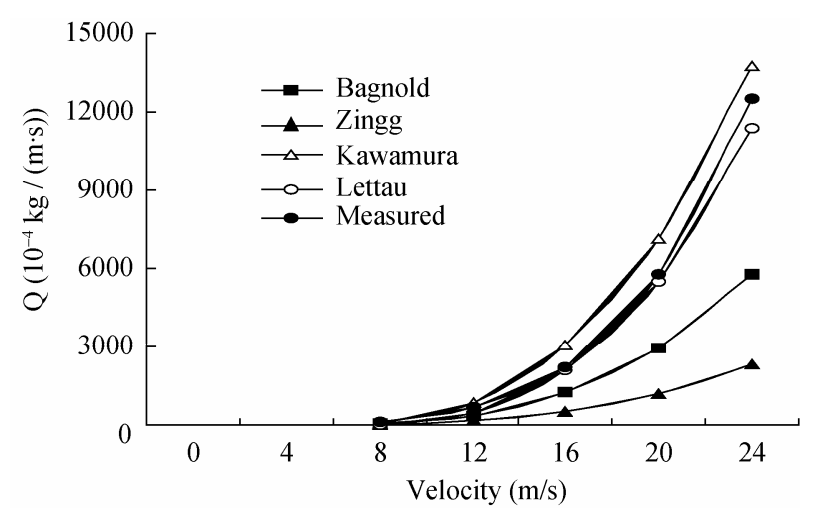

Fig. 4 Comparison between the horizontal sand flux was calculated by haricus formula and measurement

\section{Discussion and Conclusions}

In this paper, a sand-dust storm which happened in the Tazhong area of the Taklimakan Desert, in summer was used to study existing sand flux formulas. The study involved comparing the results of empirical equations with results of field tests and observations of sand flux. Large differences were found between the results for sand flux for the one Tazhong sand-dust storm when estimated by various empirical formulas. The reason for the differences between empirical and observed data is that sand grain size is taken as the main parameter in all four empirical formulas. The critical friction velocity and the sand flux are mainly determined by the sand grain size, and other influencing factors are not considered. As well, the empirical coefficient of every formula is obtained from different wind tunnel tests or field tests in different desert regions, and is not suitable for all desert regions. Therefore, the results calculated from empirical formulas underestimate the size of the sand flux. The values for sand transport flux depends mainly on wind speed and grain size of sand particles, and are also affected by factors including underlying surface conditions, terrain, temperature, surface soil moisture and air humidity. As a result, there is relative difficulty in precisely evaluating the sand transport flux during one particular sand-dust storm event. Although comparative analysis of empirical equations and instrument measurements was carried out in this paper along with analysis of the measured horizontal sand flux at the height of $2 \mathrm{~m}$, the final results are the approximation of the actual $1 \mathrm{~m}$ sand flux, because of problems with the measurement precision or instrument efficiency of the sand traps.

Some conclusions are as follows:

(1) There is consistency between the variation of friction velocity and the variation of wind speed. The friction velocity increased when the wind speed became larger, and the friction velocity exerted influence on the variations in the sand flux.

(2) According to empirical equations and instrument measurements and taking into account the underlying surface conditions, soil surface moisture and air humidity, the critical friction velocity in Tazhong area was identified as $0.24 \mathrm{~m} / \mathrm{s}$.

(3) According to field measurements, the empirical equation that best expresses the functional relation between the wind speed and horizontal sand flux at the height of $2 \mathrm{~m}$ in the Tazhong area was created, which is, $Q=10^{-6} u^{4.257}$. As a result of empirical and regional environmental constraints, the formulas of Bagnold, Zingg, Kawamura and Lettau are not all appropriate in the Tazhong area. The calculated results using Lettau's formula give the closest agreement to the field measured results. Finally, the horizontal and vertical sand transport fluxes during this sand-dust storm in the Tazhong area are respectively $258.67 \times 10^{-4} \mathrm{~kg} /(\mathrm{m} \cdot \mathrm{s})$ 
and $40.07 \times 10^{-7} \mathrm{~kg} /\left(\mathrm{m}^{2} \cdot \mathrm{s}\right)$.

\section{Acknowledgements}

This work was funded by the National Key Technology R\&D Program (2008BAC40B05-01), the National Department of Public Benefit (Meteorology) Research Foundation (GYHY

\section{References}

Abuduwaili J, Liu D W, Wu G Y. 2010. Saline dust storms and their ecological impacts in arid regions. Journal of Arid Land, 2(2): 144-150.

Bagnold R A. 1941. The Physics of Blown Sand and Desert Dunes. New York: Methuen, 1-40.

Duce R A. 1980. Long-range atmospheric transport of soil dust from Asia to the tropical North Pacific: temporal variability. Science, 209: 1522-1524.

Gillette D A, Passi R. 1988. Modeling dust emission caused by wind erosion. Journal of Geophysical Research, 93: 14234-14242.

He Q, Miao Q L, Zhang R J, et al. 2008. Analysis on aerodynamic roughness in XiaoTang in Taklimakan Desert. Journal of Desert Research, 28(6): 1011-1016.

Huo W, Li X, Ali Mamtimin, et al. 2006. Analysis on the features of sandstorms in the Tarim Basin in spring 2004. Arid Zone Research, 23(2): 210-215.

Liang Y, Liu X H, Zhang G X, et al. 2005. Study on climatic transition in a desert hinterland-Gobi desert-oasis zone in the Tarim Basin, Xinjiang. Arid Zone Research, 22(3): 332-335.

Lu H, ShaoY. 1999. A new model for dust emission by saltation bombardment. Journal of Geophysical Research, 104(D14): 16827-16841.

Lv P, Dong Z B. 2004. Current situation and existing problems in the study on the dynamics of blown sand boundary layer. Arid Zone Research, 21(2): 122-124.

Marticorena B, Bergametti G. 1995. Modeling the atmospheric dust cycle, design of a soil derived dust emission scheme. Journal of Geophysical Research, 100(D8): 16415-16430.

Shalamaiti. 1996. The characteristic of distribution of sandstorm in a period of time in the Tarim Basin. Arid Zone Research, 13(3): 21-27.

Shao Y, Mctainsh G H, Leys J F, et al. 1993. Efficiencies of sediment samplers for wind erosion measurement. Australian Journal of Soil Research, 31(4): 519-532.
201006012), Science and Technology Key Project of Xinjiang Uygur autonomous region (200833119), the Research Foundation of China Desert Meteorology (Sqj2010014, Sqj2010007), the Meteorological New Technology Projects of China Meteorological Administration (CMATG2010M29) and the Research Foundation of China Arid Meteorology (IAM201013).

Shao Y, Lu H. 2000. A simple expression for wind erosion threshold friction velocity. Journal of Geophysical Research, 105(D17): 22437-22443.

Shao Y, Raupach M R, Leys J F. 1996. A model for predicting aeolian sand drift entrainment on scales from paddock to region. Soil Research, 34 (2): 309-420.

Shao Y. 2001. A model for mineral dust emission. Journal of Geophysical Research, 106: 20239-20254.

Shen J G, Sun Z B, Zhang Q Y, et al. 2008. Preliminary study on dust emission rate over arid steppe area. Journal of Desert Research, 28 (6):1045-1049.

Shen Y B, Shen Z B, Du Y M, et al. 2004. Calculation of dust emission by wind erosion in Dunhuang Gobi surface. Plateau Meteorology, 23(5): 648-653.

Shen Y B, Shen Z B, Du Y M, et al. 2005. Factors affecting on dust emission by wind erosion and their variational characteristics. Plateau Meteorology, 24(4): 613-616.

Shen Z B, Shen Y B, Du M Y, et al. 2003. Observational result of dust emission rate over sand surface of gobi desert during dust storm. Plateau Meteorology, 22(6): 545-550.

Tegen I, Fung I. 1994. Modeling of mineral dust in the atmosphere: sources transport and optical thickness. Journal of Geophysical Research, 99: 22897-22914.

Wang P X, Sun L D, Yue P, et al. 2007. Features of dust aerosol transportation during sandstorms over Yanchi area of Ninxia Autonomous Region. Journal of Desert Research, 27(6): 1077-1079.

Zhang Q, Wei G A, Huang R H. 2001. The bulk transfer coefficients of the atmospheric momentum and sensible heat over desert and gobi in arid climate region of Northwest China. Science in China: Series D, 31(9): 783-792.

Zhang X Y, Richard Arimoto, An Z S. 1997. Dust emission from Chinese desert sources linked to variations in atmospheric circulation. Journal of Geophysical Research, 102(D23): 28041-28047. 